2001 97: 1258-1265

doi:10.1182/blood.V97.5.1258

\title{
Factors influencing in vivo transduction by recombinant adeno-associated viral vectors expressing the human factor IX cDNA
}

Amit C. Nathwani, Andrew Davidoff, Hideki Hanawa, Jun-Fang Zhou, Elio F. Vanin and Arthur W. Nienhuis

Updated information and services can be found at:

http://bloodjournal.hematologylibrary.org/cgi/content/full/97/5/1258

Articles on similar topics may be found in the following Blood collections:

Gene Therapy (389 articles)

Hemostasis, Thrombosis, and Vascular Biology (2449 articles)

Information about reproducing this article in parts or in its entirety may be found online at:

http://bloodjournal.hematologylibrary.org/misc/rights.dtl\#repub_requests

Information about ordering reprints may be found online at:

http://bloodjournal.hematologylibrary.org/misc/rights.dt|\#reprints

Information about subscriptions and ASH membership may be found online at:

http://bloodjournal.hematologylibrary.org/subscriptions/index.dtl

Blood (print ISSN 0006-4971, online ISSN 1528-0020), is published

semimonthly by the American Society of Hematology, 1900 M St, NW, Suite 200, Washington DC 20036.

Copyright 2007 by The American Society of Hematology; all rights reserved.

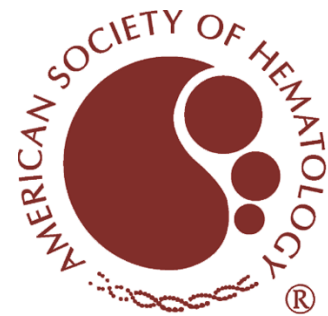




\title{
Factors influencing in vivo transduction by recombinant adeno-associated viral vectors expressing the human factor IX cDNA
}

\author{
Amit C. Nathwani, Andrew Davidoff, Hideki Hanawa, Jun-Fang Zhou, Elio F. Vanin, and Arthur W. Nienhuis
}

\begin{abstract}
Long-term expression of coagulation factor IX (FIX) has been observed in murine and canine models following administration of recombinant adeno-associated viral (rAAV) vectors into either the portal vein or muscle. These studies were designed to evaluate factors that influence rAAV-mediated FIX expression. Stable and persistent human FIX (hFIX) expression (> 22 weeks) was observed from 4 vectors after injection into the portal circulation of immunodeficient mice. The level of expression was dependent on promoter with the highest expression, $10 \%$ of physiologic levels, observed with a vector containing the cytomegalovirus (CMV) en-
\end{abstract}

hancer/ $\beta$-actin promoter complex (CAGG). The kinetics of expression after injection of vector particles into muscle, tail vein, or portal vein were similar with hFIX detectable at 2 weeks and reaching a plateau by 8 weeks. For a given dose, intraportal administration of rAAV CAGG-FIX resulted in a 1.5-fold or 4-fold higher level of hFIX compared to tail vein or intramuscular injections, respectively. Polymerase chain reaction analysis demonstrated predominant localization of the rAAV FIX genome in liver and spleen after tail vein injection with a higher proportion in liver after portal vein injection. Therapeutic levels of hFIX were detected in the major- ity of immunocompetent mice (21 of 22) following intravenous administration of rAAV vector without the development of anti-hFIX antibodies, but hFIX was not detected in 14 immunocompetent mice following intramuscular administration, irrespective of strain. Instead, neutralizing anti-hFIX antibodies were detected in all the mice. These observations may have important implications for hemophilia B gene therapy with rAAV vectors. (Blood. 2001;97:1258-1265)

(C) 2001 by The American Society of Hematology

\section{Introduction}

Hemophilia B is an X-linked bleeding disorder that results from a deficiency of blood coagulation factor IX (FIX). It affects 1 in 30000 males and is characterized by spontaneous and extended bleeding episodes that can be life threatening. Current treatment for hemophilia B with plasma-derived or recombinant FIX, although effective at preventing and arresting hemorrhage, requires frequent intravenous administration. Prophylactic therapy aimed at maintaining FIX concentration at approximately $2 \%$ of physiologic levels is effective at reducing the incidence of life-threatening bleeds and the chronic manifestations of recurrent bleeding episodes but is prohibitively expensive and not widely available.

Considerable attention has recently focused on somatic gene therapy for hemophilia B, as it offers the potential for persistent therapeutic levels of circulating FIX. Although a number of gene transfer systems have been evaluated, recombinant adenoassociated viral (rAAV) vectors show significant promise for in vivo gene therapy for hemophilia $\mathrm{B}$ in that it is possible to achieve persistent therapeutic expression of FIX leading to the correction of the bleeding phenotype in FIX knockout mice following a single administration of rAAV vectors. ${ }^{1-3}$ These studies have subsequently been extended to the hemophilia B dog model in which several groups have demonstrated sustained expression of canine FIX (cFIX), leading to amelioration of the bleeding phenotype in some cases. ${ }^{4-7}$ Recent studies have documented the safety of intramuscu- lar administration of rAAV to adult men with FIX deficiency and suggest that partially corrective levels of FIX can be achieved. ${ }^{8}$

Although these pioneering studies have clearly established the potential of rAAV-mediated gene therapy for hemophilia B, a number of issues remain unresolved. Various vectors and routes of administration have been used in different laboratories without systematic comparison. Specifically, the relative levels of FIX achieved by intramuscular injection versus systemic venous (tail vein) or hepatic venous (portal vein) injection have not been defined. The propensity of rAAV to invoke a FIX-neutralizing antibody response following intramuscular injection but not after portal vein injections in immunocompetent animals and the implications of these observations with respect to the use of the intramuscular route for human gene therapy remain unresolved..$^{3,9-11}$ Our studies were designed to address these gaps in our knowledge regarding rAAV-mediated FIX gene therapy.

\section{Materials and methods}

\section{rAAV-hFIX vector construction and purification}

The vectors used in these studies are shown diagrammatically in Figure 1. To construct rAAV vector pAV cytomegalovirus (CMV) enhancer/ $\beta$-actin promoter complex (CAGG)-FIX, a cloning intermediate (pAV CAGG) was
From the Division of Experimental Hematology, Department of Hematology/ Oncology, and Department of Surgery, St Jude Children's Research Hospital, Memphis, TN.

Submitted June 5, 2000; accepted October 16, 2000.

Supported by grant P01 HL 53749 from NHLBI Program Project, by grant 94-00 from the ASSISI Foundation of Memphis, and by the American Lebanese Syrian Associated Charities (ALSAC). A.C.N. was supported by grant 049894/114 from the Wellcome Trust.
Reprints: Arthur W. Nienhuis, Experimental Hematology, St. Jude Children's Research Hospital, 332 N. Lauderdale, Memphis, TN 38105; e-mail: arthur. nienhuis@stjude.org.

The publication costs of this article were defrayed in part by page charge payment. Therefore, and solely to indicate this fact, this article is hereby marked "advertisement" in accordance with 18 U.S.C. section 1734.

(C) 2001 by The American Society of Hematology 
A pav CAgG-Fix

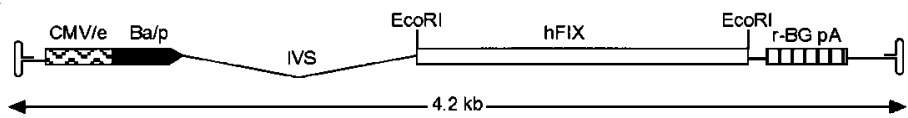

$B_{\text {PAVMSCV-FIX }}$

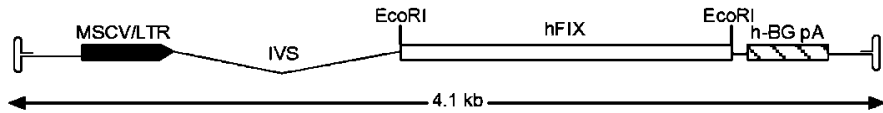

$\mathbf{C}_{\text {PAV CMVFIX }}$

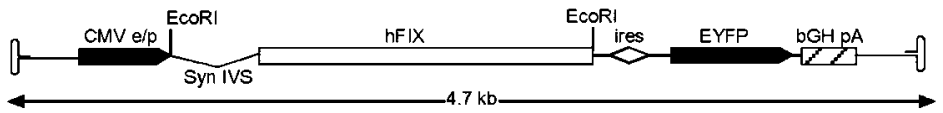

$D_{\text {PAV HBP-FIX }}$

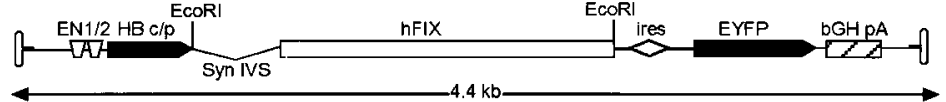

Figure 1. Structure of rAAV hFIX vector plasmids. (A) Recombinant AAV plasmid pAV CAGG-FIX consists of CMV-IE enhancer, $\beta$-actin promoter, a chicken $\beta$-actin/rabbit $\beta$ globin composite intron (CAGG), 1.6-kb human FIX cDNA (hFIX) and a rabbit $\beta$ globin polyadenylation signal (hatched box) flanked by the AAV inverted terminal repeats (ITR shown as hairpin loop). (B) pAV MSCV-FIX expression cassette consists of the $5^{\prime}$ murine stem cell leukemia virus (MSCV) long terminal repeat (LTR) together with its splice signals (IVS), hFIX cDNA and a human $\beta$ globin polyadenylation signal (hatched box) flanked by the AAV ITRs. (C) In pAV CMV-FIX-YFP, the CMV IE enhancer/promoter (CMVe/p) is followed by a synthetic intron that promotes efficient splicing (syn IVS). The promoter controls the expression of a bicistronic transcript encoding the $\mathrm{hFIX} \mathrm{gene} \mathrm{and}$ the enhanced yellow fluorescence protein (EYFP) gene separated by the encephalomyocarditis virus internal ribosomal entry site (ires). Transcription in this cassette is terminated by the bovine growth hormone polyadenylation signal (bGH pA, hatched box). (D) pAV HBPC FIX is identical to rAAV CMV-FIX except that the bicistronic transcript is under the control of the hepatitis B enhancer I and II region (ENI and ENII) and pre-core promoter derived from the hepatitis B viral (subtype ADW) genome. The EcoRI restriction enzyme used to generate the $\mathrm{hFIX}$ fragment is shown. The arrow beneath the construct indicates the size of the individual rAAV expression cassettes.

first created by the ligation of a 2.23-k base pair (bp) HincII-HindIII (blunt) fragment from plasmid pCAGGS, ${ }^{12}$ encompassing the CMV-IE enhancer, $\beta$-actin promoter, a chicken $\beta$-actin/rabbit $\beta$ globin composite intron, and a rabbit $\beta$ globin polyadenylation signal (CAGG) into the SnaBI-StuI sites of pSUB201.13 This created a plasmid in which the CAGG expression cassette was flanked by the AAV inverted terminal repeats. The hFIX complementary DNA (cDNA) was excised from pBS-FIX ${ }^{14}$ with BamHI and cloned into the $B g I I I$ site of pAV CAGG to generate pAV CAGG-FIX (Figure 1A). The pAV MSCV-FIX expression cassette consists of the 5' murine stem cell leukemia virus (MSCV) long terminal repeat derived from plasmid MGirL22Y, ${ }^{15}$ the 1.6-kb BamHI hFIX cDNA, and human $\beta$ globin polyadenylation signal flanked by pSUB201 AAV inverted terminal repeats. Plasmid pAV CMV-FIX-YFP was made by cloning a blunt-ended BamHI 1.6-kb hFIX cDNA into the blunt NsiI site of pIRES-YFP (Clontech, Palo Alto, CA). The bicistronic expression cassette was isolated by digesting with $N r u \mathrm{I}$ and Bst1107I and cloned into the SnaBI/Bst1107I site of pSUB201. pAV HBPC FIX was constructed by replacing the CMV-IE enhancer promoter complex of pAV CMV-FIX with a 734-bp fragment consisting of the hepatitis B enhancer I (ENI; nt 1068 to 1231) and II region (ENII; nt 1631 to 1741) and pre-core promoter (nt 1814 to 1900) derived from the hepatitis B viral genome (subtype ADW, GenBank accession no. V00866) and the synthetic intron from pIRES-YFP.

AAV vectors were made by the transient transfection method described before ${ }^{16}$ In brief, subconfluent $293 \mathrm{~T}$ cells either in cell factories (Nunc, Roskilde, Denmark) or plated on $15-\mathrm{cm}$ plates were cotransfected with the hFIX vector plasmid, a helper plasmid encoding the adenoviral helper genes $80-\mathrm{XX} 6$ necessary for AAV production and a packaging plasmid (XX2),${ }^{17}$ or split packing plasmids (pRep-Ad and pCMV-Cap) using the calcium phosphate method. Cells were harvested between 50 to 60 hours after transfection and lysed by incubation with $0.5 \%$ deoxycholate (Fisher Scientific, Pittsburgh, PA) in the presence of $50 \mathrm{U} / \mathrm{mL}$ Benzonase (Sigma, St Louis, MO), for 30 minutes at $37^{\circ} \mathrm{C}$. Following centrifugation at $6000 g$, the rAAV particles were isolated by affinity column chromatography. ${ }^{18}$ Standard slot-blot analysis was used to determine the vector particle titer. Contamination with wild-type (wt) AAV was determined by a polymerase chain reaction (PCR) assay described before. ${ }^{16}$ Aliquots of rAAV were periodically subjected to polyacrylamide gel electrophoresis to determine the degree of contamination with cellular proteins. The vector stocks were consistently free of contamination with wt AAV cellular and adenoviral proteins.

\section{Cell culture and in vitro transduction with rAAV-hFIX vectors}

Human embryonic kidney (293T) and human hepatoma (HepG2) cells were maintained in Dulbecco modified Eagle medium (DMEM) supplemented with $10 \%$ fetal calf serum (FCS), $100 \mathrm{U}$ penicillin per $\mathrm{mL}$, and $0.1 \mathrm{mg}$ streptomycin per $\mathrm{mL}(\mathrm{D} 10)$, at $37^{\circ} \mathrm{C}$ in a humidified atmosphere containing $5 \% \mathrm{CO}_{2}$. The liver-derived HepG2 cells express a number of clotting factors but not hFIX. ${ }^{19}$ Primary myoblasts were isolated from neonatal C57B1/6 mice as described previously ${ }^{20}$ and grown in a 1:1 mixture of F-10 and DMEM (GIBCO BRL, Gaithersburg, MD) supplemented with $20 \%$ FCS and $2.5 \mathrm{ng} / \mathrm{mL}$ basic fibroblast growth factor (Promega, Madison, WI) on collagen-coated plates. To establish that the rAAV-hFIX vectors can direct expression of hFIX, $1 \times 10^{5} \mathrm{HepG} 2$ - or C57B1/6-derived primary myoblasts were transduced overnight in serum free media with $1 \times 10^{10}$ vector genomes. Twenty-four hours conditioned media were collected on day 4 after transduction and assayed for hFIX, using the Asserachrom IX:ag enzyme-linked immunosorbent assay (ELISA) kit (American Bioproducts, Parsippany, NJ). Levels of hFIX as low as $20 \mathrm{ng} / \mathrm{mL}$ could be detected with this assay.

\section{In vivo transduction with rAAV FIX vectors}

C57B1/6 immunocompetent mice and mice with severe combined immunodeficiency disease (SCID) were obtained from Jackson Laboratory (Bar Harbor, ME). The C57B1/6 strain of mice was chosen because previous studies indicated that these animals do not produce a humoral response to hFIX.21-23 C.B-17 SCID-immunodeficient and BalB/C- and Fv129immunocompetent mice were obtained from Charles River Laboratory (Wilmington, MA). All animals were treated according to the standards set in the care and use of laboratory animals by the National Institutes of Health. For intramuscular administration, 10-week-old male mice were anesthetized with methoxyflurane, and a 1-cm longitudinal incision was made in the lower limbs to expose the quadriceps and tibialis anterior muscle. rAAV FIX vector genomes $\left(5 \times 10^{10}\right.$ to $\left.1 \times 10^{11}\right)$ in a total volume of $150 \mu \mathrm{L}$ suspended in phosphate-buffered saline was injected equally into 
the 2 muscle groups at 5 to 6 sites $(\sim 30 \mu \mathrm{L} /$ site $)$. Incisions were closed with 5-0 chromic gut sutures. The same dose of rAAV CAGG-FIX was injected into the tail veins of 10 -week-old male mice as a single bolus injection. Mice undergoing intraportal administration of rAAV vector were anesthetized with methoxyflurane. The portal vein was exposed following a right subcostal incision and displacement of intestine. The virus (between $5 \times 10^{10}$ and $1 \times 10^{11}$ genomes) in a maximum volume of $400 \mu \mathrm{L}$ was injected slowly over 2 to 3 minutes into the portal vein, using a 30-guage needle. A small piece of Gelfoam (Amersham Pharmacia, Arlington Heights, IL) was placed at the injection site to aid hemostasis before withdrawing the needle. The abdomen was closed layer to layer with 5-0 chromic gut sutures. Blood samples were collected at 14-day intervals from the retro-orbital plexus in 1/10 volume $3.2 \%$ citrate, and the hFIX concentration in murine plasma was determined by using the Asserachrom IX:ag ELISA kit (American Bioproducts). The probability of statistical difference between experimental groups was determined by one-way analysis of variance (ANOVA) and paired Student $t$ test, using GraphPad Prizm version 3.0 software (GraphPad, San Diego, CA).

\section{Nucleic acid isolation and analysis}

Organs were isolated from rAAV-FIX-treated and control mice, frozen in liquid nitrogen, and then pulverized using a mortar and pestle. High molecular weight DNA was isolated from the residual material, using Genomic-tip 100/G according to the manufacturers instruction (Qiagen, Valencia, CA). For Southern blot analysis the DNA was digested with EcoRI, electrophoresed through a $0.8 \%$ agarose gel and transferred to a nylon membrane (Hybond-N+; Amersham Pharmacia) and then hybridized with an $\alpha^{32} \mathrm{P}$-labeled 1.6-kb hFIX cDNA probe at $42^{\circ} \mathrm{C}$. The intensity of the hybridization was determined, using the STORM PhosphorImager and ImageQuant software (Molecular Dynamics, Sunnyvale, CA). To evaluate the biodistribution of rAAV-FIX vectors following intraportal and tail vein administration, $1 \mu \mathrm{g}$ of genomic DNA extracted from murine liver, spleen, kidneys, heart, and lungs was subjected to PCR using primers that amplified a 681-bp region of hFIX cDNA (5' GATCATGGCAGAATCACCAG 3' from exon 1, and 5' GCATC TTCTCCACCAACAAC $3^{\prime}$ from exon 5). PCR conditions were as follows: $94^{\circ} \mathrm{C}$ for 2 minutes and 30 cycles at $95^{\circ} \mathrm{C}$ for 30 seconds, $55^{\circ} \mathrm{C}$ for 30 seconds, and $72^{\circ} \mathrm{C}$ for 1 minute followed by a final extension of $72^{\circ} \mathrm{C}$ for 7 minutes. Standards consisting of serial dilutions of vector DNA in negative genomic DNA were used to quantitate proviral copy number. Twenty percent of the samples were electrophoresed on a $1.5 \%$ agarose gel. Integrity of DNA was determined by amplifying a 604-bp region of the murine $\beta$-actin gene, using appropriate primers $\left(5^{\prime}\right.$ TGACGGGGTCACCCACACTGTGCCCATCTA $3^{\prime}$ and 5' CTAGAAGCATTTGC GGTGGACGATGGAGGG $3^{\prime}$ ). The relative intensity of the signal was assessed digitally, using AlphaImager software version 3.24 (Alpha Innotech, San Leandro, CA).

To determine which organs expressed hFIX, total RNA was isolated from portions of liver, spleen, kidney, heart, and lungs of control mice and animals transduced with rAAV-encoding hFIX 22 weeks after portal vein administration by using RNA STAT (TEL TEST, Friendswood TX). Approximately $1 \mu \mathrm{g}$ of total RNA from each sample was subjected to the reverse transcription conditions in the presence or absence of reverse transcriptase (RT) using the 1st strand cDNA synthesis kit for RT-PCR (Roche Molecular Biochemicals, Indianapolis, IN). Of the resulting sample, $5 \mu \mathrm{L}$ was amplified in a $50-\mu \mathrm{L}$ PCR reaction as described above.

\section{Detection of anti-hFIX antibodies}

Plasma samples from mice were screened for the presence of antibody against hFIX, using an ELISA as described previously. ${ }^{3}$ In brief, plates were coated overnight with affinity-purified hFIX protein diluted to $1 \mu \mathrm{g} / \mathrm{mL}$ with $0.1 \mathrm{M} \mathrm{NaHCO}_{3}$. Diluted plasma samples $(1: 64,1: 512)$ were then applied to these wells in duplicate, and antibody against hFIX was detected with horseradish peroxidase conjugated antimouse immunoglobulin $\mathrm{G}$ (IgG; Zymed Laboratories, San Francisco, CA). Titers were estimated from a standard curve derived with serial dilutions of a mouse monoclonal anti-hFIX antibody (Roche Molecular Biochemicals). The presence of
anti-hFIX antibody was also confirmed by Western blot analysis as described by Dai et al, ${ }^{24}$ using the enhanced chemiluminescence kit (Amersham Pharmacia). Additionally, the positive samples were subjected to the Bethesda assay as described previously. ${ }^{25}$ In brief, citrated plasma diluted in Owren buffer was incubated with normal pooled plasma (Sigma) at $37^{\circ} \mathrm{C}$ for 2 hours. The residual FIX activity was then determined by using a one-step activated partial thromboplastin time. One Bethesda unit was defined as the reciprocal of the dilution of test plasma at which $50 \%$ of FIX activity is inhibited. The sensitivity of the assay was 1 Bethesda inhibitor assay unit per milliliter.

\section{Detection of anti-AAV antibodies}

Plasma samples taken at 2 weekly time points after rAAV administration into immunocompetent mice were mixed (1:100 and 1:500, 1:1000 dilutions) with $1 \times 10^{10}$ particles of a rAAV vector in which green fluorescent protein was under the control of the CAGG promoter (rAAV CAGG-GFP) and incubated for 60 minutes at $37^{\circ} \mathrm{C}$. Control reactions included plasma from transduced immunodeficient mice of the same strain. The reactions were subsequently used to transduce $1 \times 10^{5} 293 \mathrm{~T}$ cells/well in 12-well plates. Transduction efficiency was determined by assessing green fluorescent protein expression at 48 hours after exposure to the virus/antibody mix, using fluorescence-activated cell sorter analysis.

\section{Results}

\section{Comparison of rAAV-hFIX vectors}

Four different AAV vectors were constructed, each of which contained the hFIX cDNA under the transcriptional control of either constitutive (MSCV, CMV, CAGG) or liver-specific (hepatitis B enhancer/core promoter) regulatory elements (Figure 1). Splicing sequences were included between the promoter and hFIX cDNA in all the vectors, as these are critical for high-level FIX expression. ${ }^{26,27}$ The CMV and the CAGG promoter elements have been previously shown to have strong activity in muscle. ${ }^{3,28}$ The hepatitis B enhancer/core promoter complex was specifically chosen, as it has strong hepatocyte-specific activity. ${ }^{29,30}$ The activity of these rAAV-hFIX vectors was assessed in vitro by

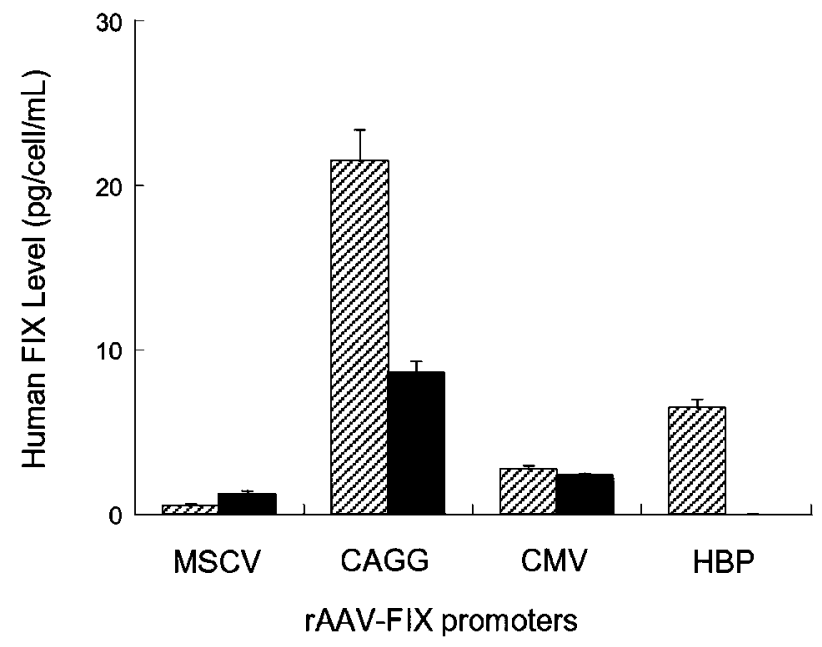

Figure 2. In vitro evaluation of rAAV-hFIX constructs. Human HepG2 hepatoma cells (striped bars) and C56BL/6-derived primary myoblasts (solid bars) were seeded in 12 -well plates at a density of $5 \times 10^{4} \mathrm{cells} /$ well. Twenty-four hours later, the cells were exposed overnight to $1 \times 10^{10}$ genomes of vectors encoding the $\mathrm{hFIX}$ gene under the control of either constitutive or liver-specific promoters. All transductions were performed in triplicate in a total volume of $500 \mu \mathrm{L}$. Twenty-four hours conditioned media were collected on day 4 after infection and assayed for hFIX by ELISA. 
Figure 3. Activity of rAAV-hFIX vectors in murine livers. In vivo activity of rAAV CAGG-FIX $(n=6$; $A)$ was compared with the 3 other vector constructs (B: CMV solid squares, $n=5$; MSCV, open squares, $n=5$; HBP, triangles, $n=6$ ) following a single injection of $1 \times 10^{1}$ vector particles into the portal vein of 7 - to 10 -week-old male C57BI/6 SCID mice. Mice were bled at the indicated number of weeks following vector administration and assayed for hFIX, using an ELISA. The results are represented as means with standard error. (C) Southern blot analysis of total DNA isolated from the liver of mice 22 weeks following administration of $1 \times 10^{11}$ vectors particles of each rAAV-hFIX vectors. DNA samples were digested with $E c o R I$, transferred to nitrocellulose membrane by Southern blot procedure, and then hybridized with a ${ }^{32} \mathrm{P}$ radiolabeled $1.5-\mathrm{kb} \mathrm{hFIX}$ cDNA probe. From right to left, lane 1 = markers, lane 2 = rAAV-FIX construct containing the MSCV promoter, lane $3=$ CAGG promoter, lane $4=\mathrm{CMV}$ promoter, lane $5=\mathrm{HBP}$ promoter, lane $6=$ DNA from a mock transduced mouse, and lanes 7 to $9=$ control mouse DNA spiked with 10, 1 and 0.1 copies per diploid genome of plasmid pAV CAGG-FIX digested with EcoRI.
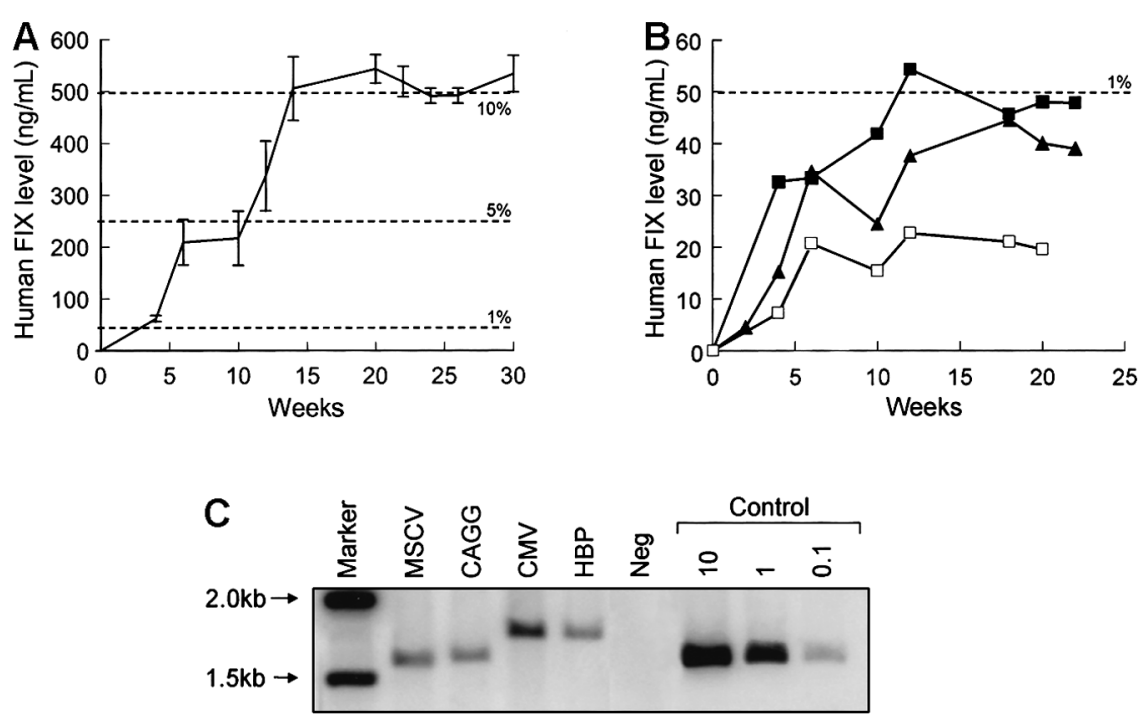

transducing $1 \times 10^{5}$ HepG2- or C57B1/6-derived primary myoblasts with $1 \times 10^{10}$ vector genomes. Twenty-four hours conditioned media were collected on day 4 after transduction and assayed for hFIX (Figure 2). hFIX was undetectable in conditioned media from untransduced cells. The highest levels of hFIX were achieved by transduction of HepG2 and myoblast cells with rAAV CAGG-FIX $(21 \pm 2$ pg FIX/cell/24 hours in HepG2 cells and $9 \pm 1 \mathrm{pg}$ FIX/cell/24 hours in myoblasts). The CMV promoter had moderate activity $(5 \pm 0.2 \mathrm{pg}$ FIX/cell/24 hours in HepG2 cells and $3 \pm 0.3 \mathrm{pg}$ FIX/cell/24 hours in myoblasts), whereas the MSCV promoter was relatively weak in both cell types $(1 \pm 0.3 \mathrm{pg}$ FIX/cell/24 hours in HepG2 cells and $1.5 \pm 0.2 \mathrm{pg}$ FIX/cell/24 hours in myoblasts). Expression of hFIX was undetectable in conditioned media derived from myoblasts transduced with rAAV HBV-FIX, whereas moderate expression $(6 \pm 0.5 \mathrm{pg} \mathrm{hFIX/cell/24}$ hours respectively) was observed in conditioned media derived from HepG2 cells transduced with this vector.

To compare the activity of rAAV-hFIX vectors in vivo, $1 \times 10^{11}$ rAAV genomes were administered into the portal vein of 7- to 10-week-old male C57B1/6 SCID mice. Figure 3 shows the level of hFIX in the plasma of recipient mice for 30 weeks following gene transfer. The profile of expression for each vector was essentially the same, and the total amount of hFIX expressed was consistent within each group but varied substantially among the different vectors. FIX levels approaching $10 \%$ of physiologic levels were detected $(506 \pm 61 \mathrm{ng} / \mathrm{mL})$ at 12 weeks and thereafter following the administration of rAAV CAGG-FIX (Figure 3A), whereas expression from the other vectors was substantially lower (20-54 ng/mL) (Figure 3B). The difference in the level of hFIX observed with rAAV CAGG-FIX compared to the other vectors was highly significant at all time points beyond 4 weeks ( $P<.001$, using one-way ANOVA). This difference in the level of expression was not related to vector copy number as shown by Southern blot analysis of genomic liver DNA from selected animals (Figure 3C). The hFIX proviral DNA was detected in livers from each animal, ranging from approximately 0.15 to 0.3 proviral copies per diploid genome. Undigested DNA produced a smear without bands, whereas DNA restricted with SexAI that cuts once within the FIX cDNA vectors yielded discrete bands whose apparent molecular weights were equivalent to that of the provirus (data not shown). These data are consistent with previous reports that indicate that AAV exists as high molecular weight head-to-tail concatamers following transduction of murine hepatocytes. ${ }^{31}$

\section{Influence of route of administration on rAAV-mediated hFIX plasma levels and distribution and expression of the rAAV genome}

rAAV CAGG-FIX or rAAV CMV-FIX genomes $\left(5 \times 10^{10}\right)$ were injected intramuscularly (quadriceps and the tibialis anterior) or intravenously via the tail or portal veins of 2 different strains of immunodeficient mice (C57B1/6J SCID or C.B-17 SCID) using the same batch of vector. The kinetics of hFIX expression for all 3 routes of administration in the $\mathrm{C} 57 \mathrm{Bl} / 6$ SCID mice was similar (Figure 4) with hFIX detectable at 2 weeks and reaching steady state levels by 8 weeks. These levels were maintained for the duration of the study (30 weeks). Intraportal administration of rAAV CAGG-FIX resulted in a 4-fold higher level of hFIX (peak $=436 \pm 25 \mathrm{ng} / \mathrm{mL}$ ) compared to intramuscular injections $($ peak $=143 \pm 66 \mathrm{ng} / \mathrm{mL})$. This difference was highly significant $(P<.01$, using one-way ANOVA). hFIX expression following administration of rAAV CAGG-FIX via the tail vein peaked at $303 \pm 77 \mathrm{ng} / \mathrm{mL}$ with steady-state levels approaching $80 \%$ of that observed in the cohort of mice receiving rAAV via the portal vein.

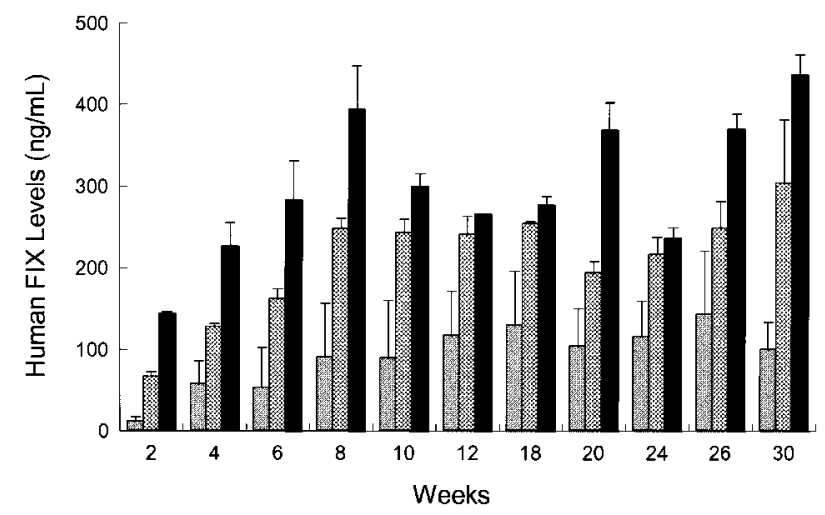

Figure 4. Influence of route of administration on rAAV-mediated hFIX expression in vivo. rAAV CAGG-FIX vector particles $\left(5 \times 10^{10}\right)$ were administered into the portal vein (solid bars), tail vein (checkered bars), or muscle (shaded bars) in 10-week-old male C57BI/6 SCID mice. Blood samples were obtained at the indicated time point after rAAV administration, and the hFIX concentration in murine plasma was determined by an ELISA. Each bar represents an average of 4 animals with SEM. 
A

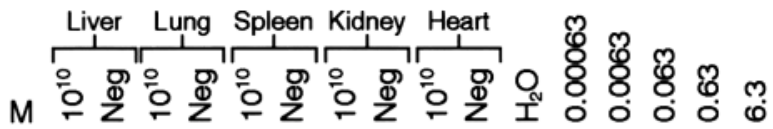

FIX

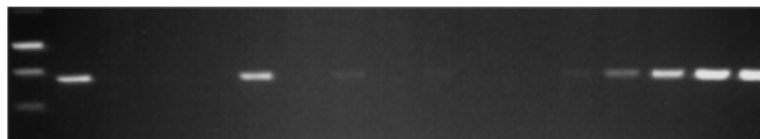

$\leftarrow 681$ bp

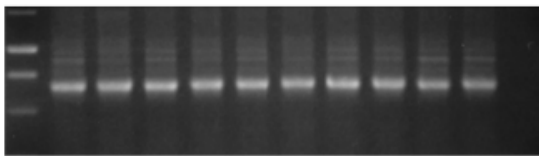

$\leftarrow 604$ bp
B

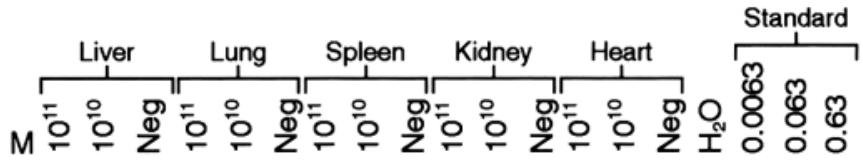

FIX

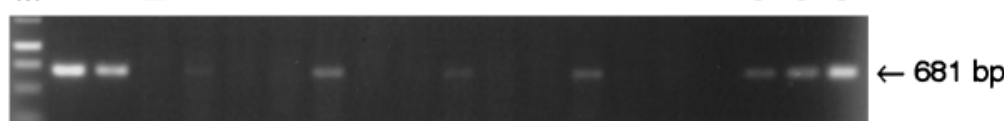

Actin

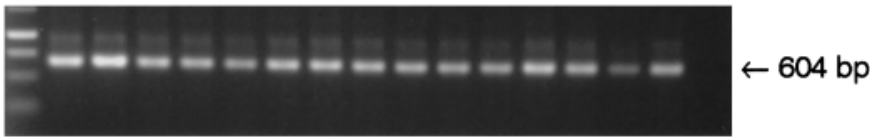

C

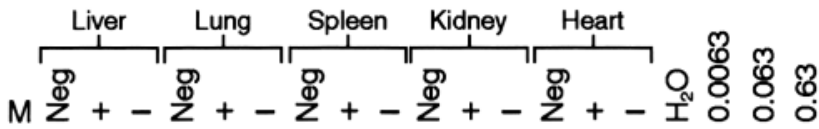

FIX

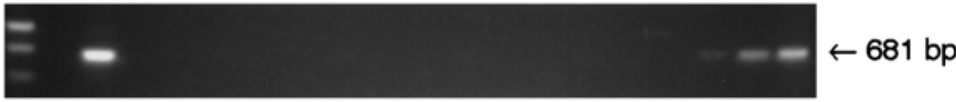

Actin

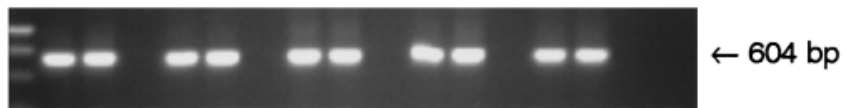

A similar pattern of expression was observed in C.B-17 SCID mice. Additionally, to determine if the difference in hFIX expression following different routes of administration was promoter specific, $1 \times 10^{11}$ genomes of rAAV CMV-FIX was injected into the portal vein or muscle of 10-week-old C.B-17 SCID mice. The level of hFIX following portal vein injection was 2.4 -fold higher than that observed following intramuscular injection $(44 \pm 15 \mathrm{ng} / \mathrm{mL}$ and $18 \pm 4 \mathrm{ng} / \mathrm{mL}$, respectively; $P<.05$ using paired $t$ test).

Vector DNA was detectable in all tissue samples examined at 22 weeks following tail vein administration of $5 \times 10^{10}$ genomes of rAAV CAGG-FIX with the majority detected in the liver and spleen (Figure 5A). Intraportal administration of the same number of rAAV CAGG-FIX particles resulted in the presence of the transgene in the liver with no evidence of spillover to the other organs, using a semiquantitative PCR assay capable of detecting $6 \times 10^{-4}$ copies per diploid genome. Significantly more spillover outside of the liver was observed following infusion of $1 \times 10^{11}$ vector particles of rAAV CAGG-FIX into the portal vein with the provirus detectable in DNA extracted from the spleen (0.005 copies/diploid genome) and heart ( 0.003 copies/diploid genome). hFIX messenger RNA (mRNA) expression, however, was only detected in the liver by RT-PCR analysis. The average vector copy number per diploid genomic equivalent in the liver corresponded to 0.2 following tail vein and 0.32 following portal vein administration of $5 \times 10^{10}$ vector particles and 0.5 following infusion of $1 \times 10^{11}$ particles
Figure 5. Analysis of biodistribution and transgene expression following tail and portal vein administration of rAAV vector. Mock transduced (neg) and rAAV CAGG-FIX transduced C57BL/6 SCID mice were killed 22 weeks after vector administration. Genomic DNA and RNA were isolated from the indicated organs. Genomic DNA $(1 \mu \mathrm{g})$ was used for PCR amplification, using primers unique to hFIX designed to amplify a 681-bp product. Proviral copy number was deduced from standards, which consisted of serial dilutions of vector DNA $\left(6.3 \times 10^{-4}\right.$ to 6.3 copies $)$ in $1 \mu \mathrm{g}$ negative genomic DNA. Integrity of DNA was determined by amplifying a 604-bp region of the murine $\beta$-actin gene and is shown at the bottom of each panel. (A) PCR amplification of genomic DNA from mice following tail vein administration of $5 \times 10^{10}$ rAAV CAGGFIX vector genomes compared with control; (B) PCR amplification of genomic DNA extracted from mice following portal vein injection of either $1 \times 10^{11}$ or $5 \times 10^{10}$ rAAV CAGG-FIX vector genomes compared with control (neg); (C) Expression analysis of hFIX mRNA by RT-PCR following portal vein injection of $1 \times 10^{11}$ rAAV CAGG-FIX particles or mock transduced mice (neg). RNA samples were amplified with $(+)$ and without $(-)$ $\mathrm{RT}$ to exclude genomic DNA amplification. into the portal vein. These copy numbers correlated well with the difference in hFIX plasma levels.

\section{Influence of route of administration on immunogenicity of $\mathrm{hFIX}$ and rAAV}

rAAV CAGG-FIX was administered to C57B1/6, Balb/C, and Fv129 strains of immunocompetent mice by the 3 routes of administration outlined above. Although a number of different batches of vector preparations were used, adequate precautions were taken to ensure that an equal number of animals in each of the cohort were transduced with the same batch of vector. Therapeutic levels of hFIX were detected (Figure 6) in 21 of 22 immunocompetent animals following either portal or tail vein administration of rAAV vector particles. The kinetics of hFIX expression in the C57B1/6 mice was comparable to that observed in its immunodeficient counterpart, although the hFIX levels were lower $\left(1 \times 10^{11}\right.$ rAAV CAGG FIX particles $=350 \pm 31 \mathrm{ng} / \mathrm{mL}, 5 \times 10^{10}$ particles $=290 \pm 73 \mathrm{ng} / \mathrm{mL}$ ). As with the immunodeficient animals, the hFIX levels observed following tail vein administration were $77 \%$ of those following intraportal infusion. Balb/C and Fv129 strains of mice had comparatively lower levels of hFIX (19\% and $62 \%$ levels in $\mathrm{C} 57 \mathrm{Bl} / 6$ mice, respectively) that may be a reflection of the strain-specific variations in transgene expression reported by others. $^{2}$ hFIX-specific antibodies were not detected by ELISA, Bethesda, or Western blot analysis in any of these animals. 

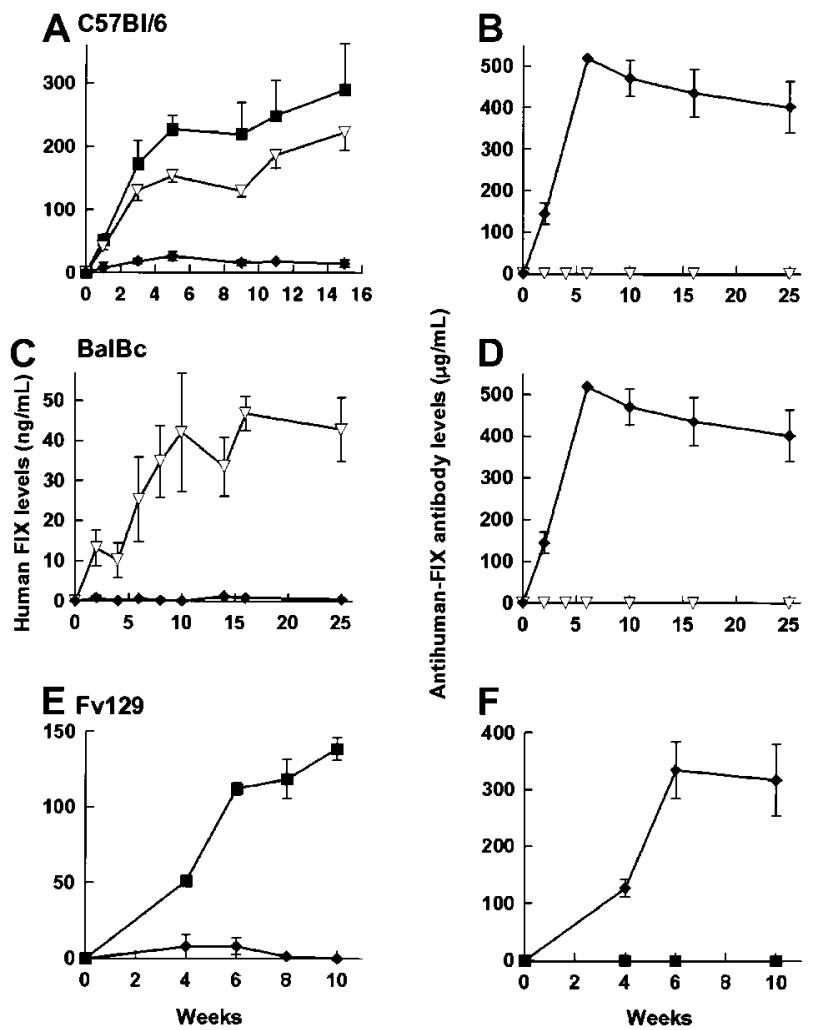

Figure 6. hFIX expression in immunocompetent animals. Expression of $\mathrm{hFIX}$ (left-hand panels) and the development of anti-hFIX antibody (right-hand panels) was examined in 6- to 8-week-old male C57/BL/6 (A,B), 4-week-old male BalBC (C,D), and 10-week-old male Fv129 (E,F) mice following administration of $5 \times 10^{10}$ particles of $\mathrm{rAAV}$ CAGG-FIX. Cohorts of C57BL/6 mice received vector through the portal vein (closed square, $n=4$ ), tail vein (inverted triangles, $n=4$ ), or into the muscle (diamonds, $n=6$ ). BalBC mice received the same vector dose through the tail vein (inverted triangles, $n=4$ ) or into the muscle (diamonds, $n=4)$. Fv129 mice received vector through the portal vein (squares, $n=4$ ) or into the muscle (diamonds, $n=4$ ). Mice were bled at the indicated number of weeks following vector administration and assayed for hFIX or the presence of anti-hFIX using an ELISA. Note that the units depicting anti-hFIX antibody levels are an estimate, as they are derived from dilutions of a monoclonal antibody. The results are represented as means with standard errors.

Intramuscular administration of $5 \times 10^{10} \mathrm{rAAV}$ CAGG-FIX particles resulted in undetectable levels of hFIX in any of the immunocompetent mice $(n=14)$ irrespective of strain. Anti-hFIX antibodies $(90-512 \mu \mathrm{g} / \mathrm{mL})$ were detected in the plasma of all these mice. The anti-hFIX antibodies had inhibitory activity in a Bethesda coagulation assay (15-25 BU/mL). The anti-hFIX antibody titer persisted at high levels for the duration of the study, suggesting continuing expression of the offending antigen. Histologic examination of the muscle in the vicinity of the injection site did not reveal any evidence of an inflammatory immune response (data not shown).

All animals that received rAAV generated a humoral antibody response to $\mathrm{AAV}$ vector particles regardless of strain or route of administration (data not shown). The level of anti-AAV antibodies varied significantly in individual mice, but there was no correlation between the route of administration and antibody levels (data not shown).

\section{Discussion}

Our studies were designed to evaluate parameters that influence the levels of FIX achieved after rAAV-mediated gene transfer. With the use of immunodeficient mouse strains, we identified the rAAV CAAG-FIX vector that has a constitutive CMV enhancer- $\beta$-actin promoter combination as giving the highest levels among the 4 vectors tested regardless of whether the vector was administered by the intramuscular route or via the systemic (tail vein) or hepatic (portal) venous circulation. The level of FIX achieved by the intraportal route $(436 \pm 25 \mathrm{ng} / \mathrm{mL})$ was approximately 4 -fold that observed with an equivalent number of vector particles injected intramuscularly. Surprisingly, tail vein injection yielded levels nearly equivalent $(60 \%-80 \%)$ to those achieved with intraportal injection. In immunocompetent mice, intramuscular injection consistently resulted in the appearance of high levels of neutralizing antibodies against hFIX in 3 separate mouse strains, whereas delivery of the vector particles into the systemic or portal venous circulation did not invoke an immune response against the human protein.

The vector with liver-specific promoter performed less well in the context of the rAAV vector design then would have been predicted from its activity in hepatocytes using adenoviral vectors. ${ }^{32}$ Conversely, the CMV enhancer- $\beta$-actin promoter combination performed better when expressing FIX in the liver than prior studies would have suggested. ${ }^{28,33}$ The levels achieved were approximately $8 \%$ to $10 \%$ of the normal hFIX levels, sufficient to convert a severe hemophiliac to a mild phenotype. These results underscore the continued unpredictable and empirical nature of vector design. Given the limitations in vector production and the problems inherent in scale up to provide sufficient vector particles to give a comparable vector dose to an adult human man, further improvement in vector design is desirable. In that context, the vector designated AAV-LSP-cFIX that contains a fragment from the thyroid hormone-binding globulin promoter and 2 copies of $\alpha 1$-microglobulin/bikunin enhancer sequences gave substantial higher levels of FIX in mice when injected via the portal vein than we have observed with a comparable dose of the rAAV CAAG-FIX vector given by the same route. ${ }^{2}$ However, when the cFIX cDNA in AAV-LSP-cFIX was replaced with its human counterpart, the FIX expression in HepG2 cells and C57B1/6 SCID mice was below that observed with rAAV CAGG-FIX (unpublished observations).

Our studies provide the first direct comparison of FIX levels achieved via the hepatic versus systemic venous circulation with the same vector preparation given at the same total dose. The fact that the systemic venous route gives $60 \%$ to $80 \%$ of the levels achieved by intraportal injection undoubtedly reflects the known propensity of rAAV to collect in liver cells. ${ }^{34}$ An important practical implication of our results is that selective delivery via the hepatic artery through a percutaneous catheter, a technically less complex and risky procedure than portal vein injections in humans, may be the preferred route for rAAV-FIX administration to patients with hemophilia.

Our results suggest dose-dependent "spillover" of vector particles injected into the portal circulation. At a dose of $5 \times 10^{10}$ vector particles, PCR analysis detected the rAAV genome predominantly in liver, whereas, at a dose of $1 \times 10^{11}$ particles, a larger proportion of the vector genome was found in the spleen and other organs (Figure 4). Similar dose-dependent spillover has been observed when vector particles were given via the intramuscular route (ORDA web site, http://www.nih.gov/od/oba/3-99RAC.htm). Restricting the distribution of rAAV after hepatic artery injection to the liver seems desirable and may require that the dose of vector particles is kept within certain defined limits. This consideration further underscores the need to use a vector configuration that maximizes liver-specific expression. 
We used 2 different promoters to demonstrate that the liver is a more potent site for rAAV-mediated FIX production than muscle irrespective of mouse strain. This may reflect the fact that the liver is the natural site of FIX synthesis and has the necessary machinery for posttranslational modification of the mature protein. Although processing of FIX in myotubules has been documented, ${ }^{35}$ the relative efficiency of the gamma-carboxylation in muscle versus liver is unknown. More important, however, is the issue of inhibitory antibodies to transgene products. An earlier study ${ }^{3}$ reported neutralizing antibodies directed against hFIX following intramuscular injection of rAAV-hFIX vector particles in C57B1/6 mice. Neutralizing antibodies against human $\alpha 1$-antitrypsin have also been documented following intramuscular administration of rAAV vector. ${ }^{36}$ It was unclear, however, if this immune response was mouse strain specific or related to contamination of the vector preparation with adenovirus particles or cellular proteins. These questions have now been resolved in that we have identified neutralizing antibody formation in 3 mouse strains following intramuscular injection of rAAV preparations that were entirely free of adenoviral particles or protein contamination. These same vector preparations failed to invoke antibodies against hFIX when given via the venous circulation to the same strains of mice. There can be little doubt that the intramuscular route provides a different immune stimulus to the same protein in mice than does delivery of vector particles predominantly to the liver. The precise mechanism for this difference remains unclear, but it is possible that ectopic expression of proteins, such as clotting factor, in a site like the muscle could generate a novel immune response perhaps due to the formation of neoantigens as a result of improper processing of the transgene protein. In addition, hFIX antigen presentation following gene transfer into the muscle may be mediated through a different pathway.

Do these findings have implications with regard to human gene therapy applications? Three patients with hemophilia have now been given rAAV-hFIX particles via the intramuscular route without evidence of formation of neutralizing antibodies against FIX. ${ }^{8}$ However, a relatively low dose of rAAV vector particles was administered. Furthermore, each of the patients had a missense mutation in their FIX gene so that tolerance to FIX had undoubtedly been induced during normal development. A prior study in hemophilic dogs with a missense mutation in their FIX gene is also of some interest. ${ }^{6}$ In 2 of 5 animals given rAAV-cFIX, antibodies against cFIX were detected by Western blot analysis, with transient reduction in antigen levels. Further studies in this dog model indicate that the tendency to form neutralizing antibodies toward the transgene product following intramuscular administration is partially determined by the vector dose. ${ }^{10}$ All together, the data suggest that tolerance can be broken at least transiently in such animals.

Liver-targeted delivery through the hepatic artery seems the preferred route for administration of rAAV-FIX particles, both because of the potentially higher levels of FIX achieved and the absence of an immune response. Available evidence indicates that rAAV forms head-to-tail concatamers, perhaps via a rate-limiting dimer intermediate, and integrates into liver cell chromosomes. ${ }^{37,38}$ Thus, stable production of FIX observed in animal studies is likely to persist. Antibodies to AAV, previously observed by other investigators, ${ }^{39,40}$ were also documented in our studies presumably precluding readministration of rAAV of the same serotype. If necessary, rAAV of different serotypes could be readministered to augment FIX production over time. ${ }^{41}$ Overall, rAAV seemed to hold significant promise for the treatment of hFIX deficiency.

\section{Acknowledgments}

We wish to thank Jean Johnson for her outstanding assistance in preparation of the manuscript and Professor George Brownlee for his gift of pBS-FIX.

\section{References}

1. Snyder RO, Miao CH, Patijn GA, et al. Persistent and therapeutic concentrations of human factor IX in mice after hepatic gene transfer of recombinant AAV vectors. Nat Genet. 1997;16:270-276.

2. Wang L, Takabe K, Bidlingmaier SM, III CR, Verma IM. Sustained correction of bleeding disorder in hemophilia B mice by gene therapy. Proc Natl Acad Sci U S A. 1999;96:3906-3910.

3. Herzog RW, Hagstrom JN, Kung SH, et al. Stable gene transfer and expression of human blood coagulation factor IX after intramuscular injection of recombinant adeno-associated virus. Proc Natl Acad Sci U S A. 1997;94:5804-5809.

4. Chao $H$, Samulski R, Bellinger $D$, Monahan $P$, Nichols T, Walsh C. Persistent expression of canine factor IX in hemophilia B canines. Gene Ther. 1999;6:1695-1704

5. Wang L, Nichols TC, Read MS, Bellinger DA, Verma IM. Sustained expression of therapeutic level of factor IX in hemophilia B dogs by AAVmediated gene therapy in liver. Mol Ther. 2000;1: 154-158.

6. Herzog RW, Yang EY, Couto LB, et al. Long-term correction of canine hemophilia $B$ by gene transfer of blood coagulation factor IX mediated by adeno-associated viral vector. Nat Med. 1999;5:5663.

7. Snyder RO, Miao C, Meuse L, et al. Correction of hemophilia $B$ in canine and murine models using recombinant adeno-associated viral vectors. Nat Med. 1999;5:64-70.

8. Kay MA, Manno CS, Ragni MV, et al. Evidence for gene transfer and expression of factor IX in haemophilia B patients treated with an AAV vector. Nat Genet. 2000;24:257-261.

9. Monahan PE, Samulski RJ, Tazelaar J, et al. Direct intramuscular injection with recombinant AAV vectors results in sustained expression in a dog model of hemophilia. Gene Ther. 1998;5:40-49.

10. Herzog RW, Fields PA, Arruda VR, et al. Characterization of $\mathrm{B}$ - and T-cell response against factor $\mathrm{IX}$ in AAV vector-based gene therapy for canine hemophilia B. Mol Ther. 2000;1 (Part 2):S27.

11. Armstrong E, Fields PA, Arruda VR, et al. Immune response in hemophilia $B$ mice expressing a species specific transgene. Mol Ther. 2000; 1(Part 2):S29.

12. Niwa H, Yamamura K, Miyazaki J. Efficient selection for high-expression transfectants with a novel eukaryotic vector. Gene. 1991;108:193-199.

13. Samulski RJ, Chang LS, Shenk TE. A recombinant plasmid from which an infectious adenoassociated virus genome can be excised in vitro and its use to study viral replication. J Virol. 1987; 61:3096.

14. Page SM, Brownlee GG. An ex vivo keratinocyte model for gene therapy of hemophilia B. J Invest Dermatol. 1997;109:139-145.

15. Persons DA, Allay JA, Allay ER, et al. Retroviralmediated transfer of the green fluorescent protein gene into murine hematopoietic cells facilitates scoring and selection of transduced progenitors in vitro and identification of genetically modified cells in vivo. Blood. 1997:90:1777-1786.
16. Nathwani AC, Hanawa $H$, Vandergriff J, Kelly $P$, Vanin EF, Nienhuis AW. Efficient gene transfer into human cord blood CD34+ cells and the CD34+. Gene Ther. 2000;7:183-195.

17. Xiao X, Li J, Samulski RJ. Production of high-titer recombinant adeno-associated virus vectors in the absence of helper adenovirus. J Virol. 1998; 72:2224-2232.

18. Clark KR, Liu X, McGrath JP, Johnson PR. Highly purified recombinant adeno-associated virus vectors are biologically active and free of detectable helper and wild-type viruses. Hum Gene Ther. 1999;10:1031-1039.

19. Fair DS, Bahnak BR. Human hepatoma cells secrete single chain factor $\mathrm{X}$, prothrombin, and antithrombin III. Blood. 1984;64:194-204.

20. Springer ML, Blau HM. High-efficiency retroviral infection of primary myoblasts. Somat Cell Mol Genet. 1997;23:203-209.

21. Michou AI, Santoro L, Christ M, Julliard V, Pavirani $A$, Mehtali $M$. Adenovirus-mediated gene transfer: influence of transgene, mouse strain and type of immune response on persistence of transgene expression. Gene Ther. 1997;4:473-482.

22. Barr D, Tubb J, Ferguson D, et al. Strain related variations in adenovirally mediated transgene expression from mouse hepatocytes in vivo: comparisons between immunocompetent and immunodeficient inbred strains. Gene Ther. 1995;2: 151-155.

23. Kay MA, Landen CN, Rothenberg SR, et al. In 
From www.bloodjournal.org at UCL Library Services on September 15, 2008. For personal use only.

vivo hepatic gene therapy: complete albeit transient correction of factor IX deficiency in hemophilia B dogs. Proc Natl Acad Sci U S A. 1994;91: 2353-2357.

24. Dai Y, Schwarz EM, Gu D, Zhang WW, Sarvetnick N, Verma IM. Cellular and humoral immune responses to adenoviral vectors containing factor IX gene: tolerization of factor IX and vector antigens allows for long-term expression. Proc Natl Acad Sci U S A. 1995;92:1401-1405.

25. Kung SH, Hagstrom JN, Cass D, et al. Human factor IX corrects the bleeding diathesis of mice with hemophilia B. Blood. 1998;91:784-790.

26. Kurachi S, Hitomi Y, Furukawa M, Kurachi K. Role of intron I in expression of the human factor IX gene. J Biol Chem. 1995;270:5276-5281.

27. Jallat S, Perraud F, Dalemans W, et al. Characterization of recombinant human factor IX expressed in transgenic mice and in derived transimmortalized hepatic cell lines. EMBO J. 1990;9: 3295-3301.

28. Daly TM, Okuyama T, Vogler C, Haskins ME, Muzyczka N, Sands MS. Neonatal intramuscular injection with recombinant adeno-associated virus results in prolonged beta-glucuronidase expression in situ and correction of liver pathology in mucopolysaccharidosis type VII mice. Hum Gene Ther. 1999;10:85-94.
29. Loser P, Sandig V, Kirillova I, Strauss M. Evaluation of HBV promoters for use in hepatic gene therapy. Biol Chem Hoppe Seyler. 1996;377:187193.

30. Hafenrichter DG, Wu X, Rettinger SD, Kennedy SC, Flye MW, Ponder KP. Quantitative evaluation of liver-specific promoters from retroviral vectors after in vivo transduction of hepatocytes. Blood. 1994;84:3394-3404.

31. Miao $\mathrm{CH}$, Snyder RO, Schowalter DB, et al. The kinetics of rAAV integration in the liver. Nat Genet. 1998,19:13-15

32. Sandig V, Loser P, Lieber A, Kay MA, Strauss M. HBV-derived promoters direct liver-specific expression of an adenovirally transduced LDL receptor gene. Gene Ther. 1996;3:1002-1009.

33. Nakai H, Herzog RW, Hagstrom JN, et al. Adenoassociated viral vector-mediated gene transfer of human blood coagulation factor IX into mouse liver. Blood. 1998;91:4600-4607.

34. Ponnazhagan S, Mukherjee P, Wang XS, et al. Adeno-associated virus type 2-mediated transduction in primary human bone marrow-derived $\mathrm{CD}^{+} 4^{+}$hematopoietic progenitor cells: donor variation and correlation of transgene expression with cellular differentiation. J Virol. 1997;71:82628267.

35. Arruda VR, Hagstrom JN, Herzog RW, et al. Fac- tor IX synthesized in dog and human muscle cells has specific activity comparable to plasmaderived factor IX. Blood. 1998;92(suppl 1):2836.

36. Song S, Morgan M, Ellis T, et al. Sustained secretion of human alpha-1-antitrypsin from murine muscle transduced with adeno-associated virus vectors. Proc Natl Acad Sci U S A. 1998;95: 14384-14388.

37. Nakai H, Iwaki Y, Kay MA, Couto LB. Isolation of recombinant adeno-associated virus vector-cellular DNA junctions from mouse liver. J Virol. 1999; 73:5438-5447.

38. Miao $\mathrm{CH}$, Nakai $\mathrm{H}$, Thompson $\mathrm{AR}$, et al. Nonran dom transduction of recombinant adeno-associated virus vectors in mouse hepatocytes in vivo: cell cycling does not influence hepatocyte transduction. J Virol. 2000;74:3793-3803.

39. Chirmule N, Propert K, Magosin S, Qian Y, Qian $\mathrm{R}$, Wilson J. Immune responses to adenovirus and adeno-associated virus in humans. Gene Ther. 1999;6:1574-1583.

40. Chirmule N, Xiao W, Truneh A, et al. Humoral immunity to adeno-associated virus type 2 vectors following administration to murine and nonhuman primate muscle. J Virol. 2000;74:2420-2425.

41. Halbert CL, Rutledge EA, Allen JM, Russell DW, Miller AD. Repeat transduction in the mouse lung by using adeno-associated virus vectors with different serotypes. J Virol. 2000;74:1524-1532. 